\title{
Correction to "Answers to Common Clinical Questions"
}

In the Editors' Note titled "Answers to Common Clinical Questions,"1 the abstract incorrectly states that an article appears in the January/February 2012 issue regarding "how to influence care outcomes: highleverage, not just measurable, activities." This article did not appear in the January/February 2012 issue; it appeared in the March/April 2012 issue. The electronic version on the Journal of the American Board of Family Medicine's website has been corrected. We apologize for the error, and we regret any confusion or inconvenience it may have caused. (doi: 10.3122/jabfm.2012.03.120072.)

\section{Reference}

1. Bowman MA, Neale AV. Answers to common clinical questions. J Am Board Fam Med 2012;25:1-4. 